\title{
Diagnostic issues in a family with late onset type 2 neurofibromatosis
}

\author{
D G R Evans, D Bourn, A Wallace, R T Ramsden, J D Mitchell, T Strachan
}

\begin{abstract}
We report a family with type 2 neurofibromatosis and late onset tumours. Five members of this family have developed hearing loss late in life, two of whom have only been shown to have the diagnosis in their seventies, and three other obligate gene carriers died undiagnosed at 64,72 , and 78 years of age. A missense mutation at the C-terminal end of the NF2 protein has been identified in this family and segregates with disease. The use of highly polymorphic markers for predictive testing is also shown. There appears to be an autosomal dominant form of spinocerebellar degeneration which is segregating separately to NF2 in this family, which created a diagnostic dilemma.
\end{abstract}

( $(\mathcal{H}$ Med Genet 1995;32: 470-474)

Type 2 neurofibromatosis (NF2) is an autosomal dominant disorder predisposing to tumours of neurogenic origin. The great majority of people with NF2 will present in the second and third decades with bilateral vestibular schwannomas (VS) and many will also develop schwannomas of other cranial nerves, spinal nerve roots, and peripheral nerves. ${ }^{12}$ In addition about $50 \%$ will also develop cranial or spinal meningiomas. ${ }^{1}$ It has been suggested that there is concordance of disease severity in families, but not between them, and that this may reflect a genotype/phenotype correlation. ${ }^{34}$ Recently, the NF2 gene has been mapped to chromosome 22q12 and identified as a member of a family of genes which encode proteins thought to interact with membrane and cytoskeletal proteins including genes encoding merlin, ezrin, radixin, erythrocyte band 4.1 protein, and others. ${ }^{56}$ Characterisation of the gene coding sequence $e^{56}$ and identification of intron/exon boundaries ${ }^{7}$ has permitted mutation screening. We report a family which is unusual for the late onset of symptoms in which we have identified the causative mutation and in whom predictive testing is easily achieved with linked markers.

\section{Case report}

The family pedigree is shown in fig 1 and clinical details in the table.

The proband (401), a woman, presented at the age of 30 years with progressive hearing loss starting initially on the right side. She then developed severe headaches secondary to hydrocephalus and underwent a CT scan aged 33 years which showed bilateral large VS $(3 \mathrm{~cm})$. In the following 16 months she underwent excision of both tumours through a translabyrinthine approach as well as shunting procedures. Following these operations she was completely deaf, but has learnt to lip read well. Since then she has had three skin lumps excised from her arms all of which were reported as "neurofibromas". However, the pathology has not been reviewed. In addition to this she has two further intracutaneous plaques, but no café au lait patches. She has recently undergone surgery to remove a large cervical spinal schwannoma.
Features of NF2 and spinocerebellar degeneration in family members

\begin{tabular}{|c|c|c|c|c|c|c|c|c|c|c|}
\hline Subject & Age (y) & Dfns onset & $B V S$ & Spnl tum & Cranl mening & $C A L$ & Skin tum & Tremor & Ataxia & NF2 mut \\
\hline 101 & +72 & 52 & $\mathrm{dk}$ & $\mathrm{dk}$ & $\mathrm{dk}$ & $\mathrm{dk}$ & $\mathrm{dk}$ & $\mathrm{dk}$ & $\mathrm{dk}$ & $\mathrm{dk}$ \\
\hline 201 & +64 & 44 & $\mathrm{dk}$ & $\mathrm{dk}$ & $\mathrm{dk}$ & $\mathrm{dk}$ & $\mathrm{dk}$ & $\mathrm{dk}$ & $\mathrm{dk}$ & $\mathrm{dk}$ \\
\hline 202 & +78 & 50 & $\mathrm{dk}$ & $\mathrm{dk}$ & $\mathrm{dk}$ & $\mathrm{dk}$ & $\mathrm{dk}$ & $\mathrm{dk}$ & $\mathrm{dk}$ & $\mathrm{dk}$ \\
\hline 203 & +86 & no & $\mathrm{dk}$ & $\mathrm{dk}$ & $\mathrm{dk}$ & $\mathrm{dk}$ & $\mathrm{dk}$ & $\mathrm{dk}$ & $\mathrm{dk}$ & $\mathrm{dk}$ \\
\hline 301 & 70 & 61 & yes & no & no & no & no & yes & yes & yes \\
\hline 302 & 68 & no & - & - & - & no & no & yes & yes & no \\
\hline 303 & 72 & no & - & - & - & no & no & no & no & no \\
\hline 304 & 63 & no & - & - & - & $\mathrm{dk}$ & $\mathrm{dk}$ & $\mathrm{dk}$ & $\mathrm{dk}$ & $\mathrm{dk}$ \\
\hline 305 & 72 & 52 & yes & no & yes & no & no & no & no & yes \\
\hline 306 & 59 & 43 & yes & yes & yes & no & no & no & no & yes \\
\hline 307 & 66 & no & - & $\mathrm{dk}$ & $\mathrm{dk}$ & $\mathrm{dk}$ & $\mathrm{dk}$ & $\mathrm{dk}$ & $\mathrm{dk}$ & $\mathrm{dk}$ \\
\hline 401 & 37 & 30 & yes & yes & no & no & 5 & no & no & yes \\
\hline 402 & 41 & no & no & no & no & no & no & yes & yes & no \\
\hline 403 & 21 & no & - & - & - & $\mathrm{dk}$ & $\mathrm{dk}$ & $\mathrm{dk}$ & $\mathrm{dk}$ & $\mathrm{dk}$ \\
\hline 404 & 28 & no & - & - & 一 & no & no & no & no & no \\
\hline 405 & 37 & no & - & - & - & $\mathrm{dk}$ & $\mathrm{dk}$ & no & no & no \\
\hline 406 & 33 & no & - & - & - & $\mathrm{dk}$ & $\mathrm{dk}$ & $\mathrm{dk}$ & $\mathrm{dk}$ & $\mathrm{dk}$ \\
\hline 501 & 15 & no & - & - & - & no & no & no & no & yes \\
\hline 502 & 12 & no & - & - & - & no & no & no & no & yes \\
\hline
\end{tabular}

$\mathrm{CAL}=$ café au lait; tum = tumour; spnl = spinal; cranl mening = cranial meningioma; $\mathrm{BVS}=$ bilateral vestibular schwannomas on scan; Dfns = deafness; mut $=$ mutation

$\mathrm{dk}=$ where the presence of a feature was not known; $-=$ no evidence clinically; no is entered for CNS tumours when CT or MRI must have been performed.

No evidence for cataracts was found on slit lamp examination in 306, 401, 501, and 502 and on ophthalmoscopy in 301 and 305.
Correspondent

Received 17 August 1994 Revised version accepted for
publication 1 February 1995 


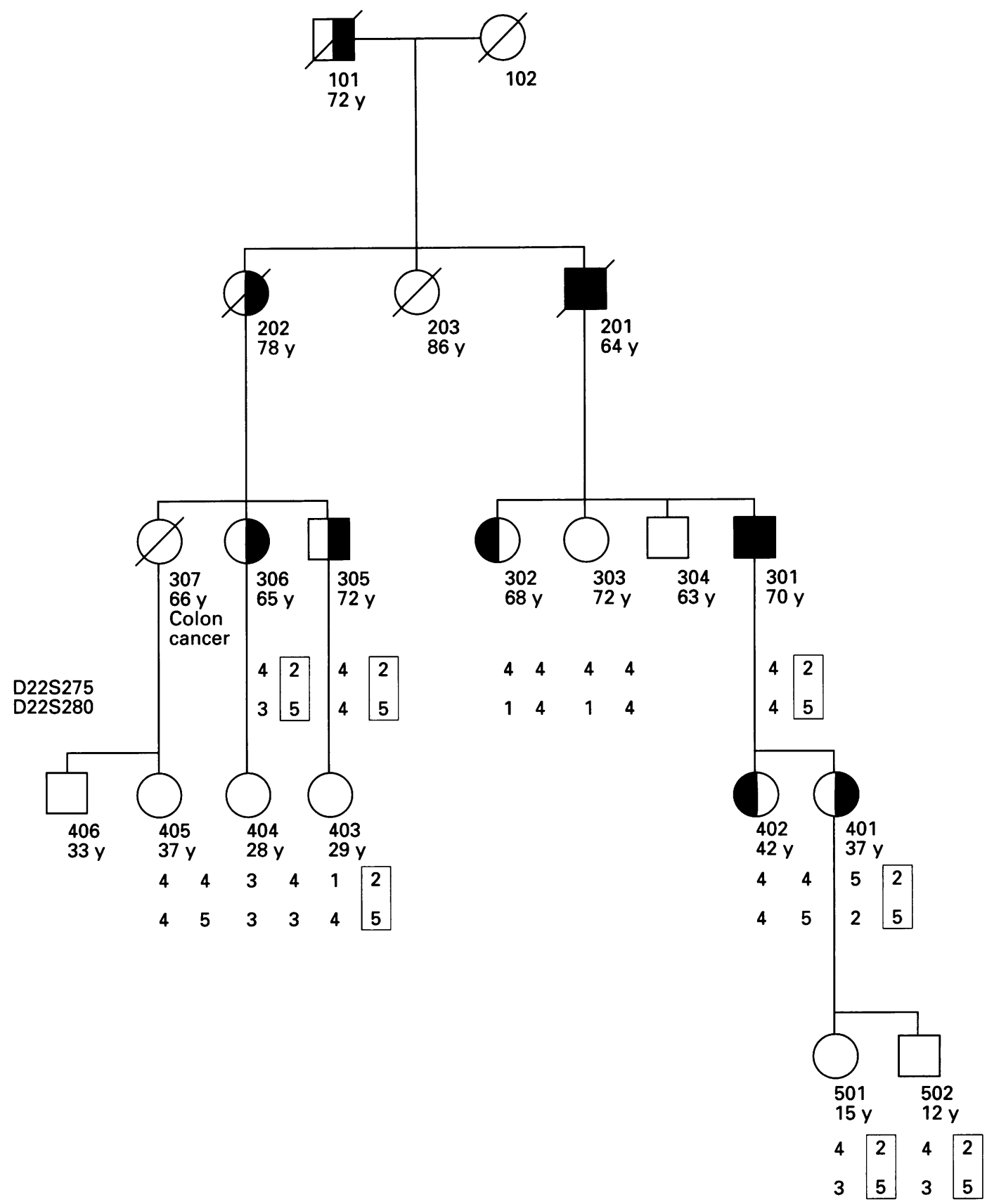

Figure 1 Pedigree symbols shaded in the left half represent people with evidence of spinocerebellar degeneration; those shaded in the right half represent people with bilateral deafness and presumed or proven NF2. Quoted age in years is age at death or current age. Boxed haplotypes represent inferred NF2 associated haplotype.

The father of 401 (301) presented aged 22 years with a progressive ataxia and, more latterly, incessant tremor. He only began to notice hearing loss at the age of 61 years and still retains some serviceable hearing. On examination aged 64 years he had marked tremor especially in his hands as well as cerebellar ataxia. Nerve conduction studies showed an axonal degenerative pattern, but brain stem evoked potentials and a CT scan were all reported as normal. In the light of the history of NF2 in his daughter the CT scan was repeated one year later with contrast, but no abnormality was detected in the acoustic meati or canals. In view of the clear history of a similar pattern of ataxia and tremor in his father (201), sister (302), and daughter (402) it was felt that these features represented an autosomal dominant spinocerebellar degeneration syndrome. An
MRI scan was arranged when he was 70 years of age as a cousin (306) had recently been diagnosed as having bilateral VS. This clearly showed bilateral enhancing lesions in the acoustic meati.

A cousin of 401 (305) presented with hearing loss aged 52 years which was attributed to his work as an engineer. This became progressively worse until he developed seizures aged 71 years. After his sister (306) was diagnosed with NF2 he underwent a CT scan which showed a $9 \mathrm{~cm}$ frontal meningioma, but no evidence of VS. However, MRI scanning showed intracanalicular tumours.

\section{Molecular analysis}

Details of the methods for molecular analysis are shown in the appendix. ${ }^{8}$ 


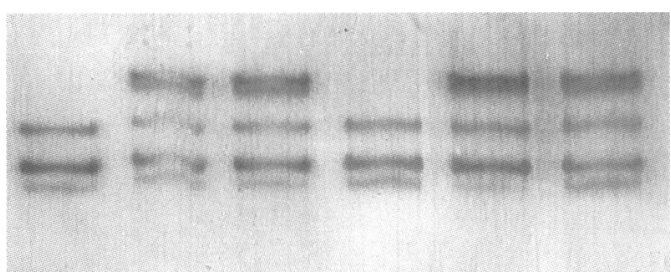

Figure 2 SSCP analysis. The PCR products analysed correspond to exon 15 of the NF2 gene spanning codons 525-579. Lane 1 subject 402, lane 2 subject 401, lane 3 subject 301, lane 4 subject 302, lane 5 subject 305, lane 6 subject 305. Patient specific bands can be seen for affected subjects 301, 305, 306, and 401.

\section{Results}

The haplotypes for the flanking microsatellite markers S275 and S280 are shown on the pedigree (fig 1). Linkage predictions for 302, $303,402,404$, and 405 showed a risk of $<0 \cdot 1 \%$ chance of being affected. Subjects 403, 501, and 502 were at $>99.9 \%$ chance of being affected.

Genomic DNA samples prepared from peripheral blood from two affected members of the family (306 and 401) were amplified with intron specific primers amplifying across all the exons of the NF2 gene. ${ }^{7}$ Amplified fragments were screened for patient specific variants using SSCP analysis. Fig 2 shows the variant bands detected in exon 15 amplified material. Cloning and sequence analysis (fig 3) of the mutant allele showed a $\mathrm{T} 1604 \rightarrow \mathrm{C}$ transition causing a Leu $\rightarrow$ Pro change at position 535 (numbering as in reference 5). This change also abolishes a PstI site (CTGCAG) in the genomic DNA allowing direct detection of the mutation. Analysis of other family members indicated that this mutation is present in all people predicted to be at risk by linkage analysis.

From the combination of mutation analysis and linkage it is clear that the history of deafness dating back to subject 101 was the result of a mutation in the NF2 gene. Subjects 101, 201, and 202 were all deaf in the last 20 years of life but died from apparently unrelated causes. Members of this family who were not clearly affected were offered predictive testing; subjects 302 and 402 who exhibited ataxia and

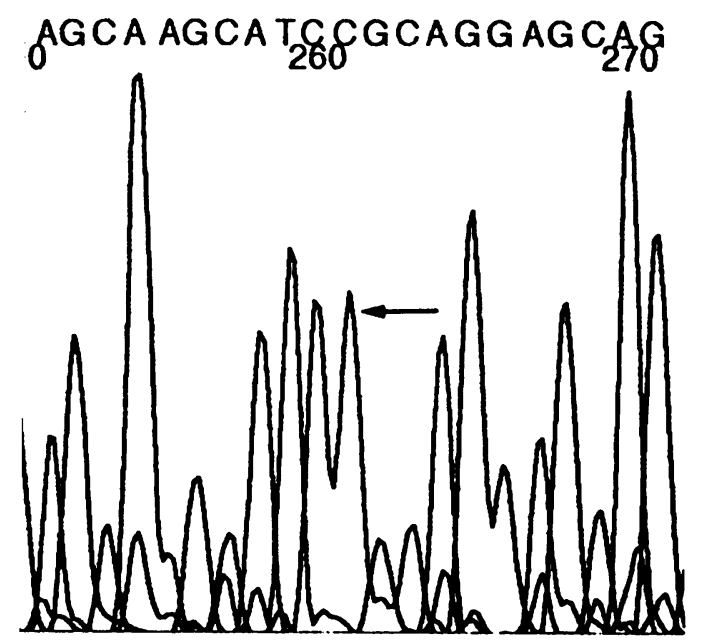

Figure 3 DNA sequencing profile of relevant region of NF2 gene containing T1604 $\rightarrow C$ transition (arrowed). tremor had clearly not inherited the gene as was the case for 303, 405, and 403. However, both the children of 401 who continued to have normal brain stem evoked responses and subject 403 who is asymptomatic aged 29 years were shown to have inherited the family mutation.

\section{Discussion}

The variability of disease course between families and the relatively similar course within families has led previous authors to suggest a subdivision of NF2 into severe (Wishart) and mild (Gardner) subgroups. ${ }^{49}$ With the recent cloning of the NF2 gene ${ }^{56}$ there has inevitably been a search for the elusive genotype/phenotype correlation to explain this. Early reports of germline mutations have not provided any concrete evidence for this, ${ }^{1011}$ but we have previously reported a family which has a large deletion encompassing the NF2 gene in which there is a mild phenotype. ${ }^{12}$ The spectrum of pathological mutations reported in NF2 patients include relatively few missense mutations. ${ }^{671013}$ The residue affected in this instance, Leu 535 , is conserved in the murine NF2 homologue and in human moesin. ${ }^{5}$ All other members of the NF2 gene family encode products with a valine residue in this position. As valine and leucine have very similar chemical properties, a high degree of conservation is indicated at this codon position. Such a nonconservative Leu $\rightarrow$ Pro change would be predicted to affect the $\alpha$ helical domain of the NF2 protein. This mutation has not been observed in a survey of a large number of normal alleles, and our analysis of all of the exons of the NF2 gene has failed to detect any other mutations in affected family members.

Currently SSCP is able to detect 30 to $60 \%$ of mutations in the NF2 gene from genomic DNA. As $50 \%$ of people are new mutations this offers a substantial boost to the ability to perform presymptomatic predictive tests. However, complete analysis of the whole gene may take several months. We have also been able to show the usefulness of linkage in this family with eight out of eight subjects successfully undergoing presymptomatic testing with linked markers. There is currently no evidence for heterogeneity in $\mathrm{NF} 2^{14}$ and linkage diagnosis is therefore appropriate even in small nuclear families. ${ }^{15}$ There is clearly controversy as to whether predictive testing should be offered in childhood, particularly in a family like this one, where onset has been exclusively well into adulthood. However, there are exceptions even in mild families, such as subject 401 , and overall $10 \%$ of people with NF2 present before 10 years of age. ${ }^{1}$ A decision to offer presymptomatic testing at the inception of more comprehensive screening at 10 to 12 years, ${ }^{3}$ or to delay this until the person can make a more informed choice at around 18 years, should take into consideration the severity of the phenotype in the family and other individual considerations.

Before the ability to detect tiny tumours with MRI scans (it is important to note that CT 
scans failed to detect the VS in both 306 and 301 ), families such as the one we have described would have gone completely undiagnosed, as indeed they did for over 50 years. The Pennsylvanian family originally reported by Gardner and Frazier ${ }^{16}$ included many family members who went deaf late in life, although more recent generations presented much earlier, some dying in their twenties of VS related problems. One obligate gene carrier female in the second generation died at the age of 85 years, although the age at onset of deafness was not known. Despite the fact that three members of our family died undiagnosed in their sixties and seventies, they were all symptomatic by their fifties. MRI scanning would indubitably have shown bilateral VS and this family does not therefore show any real evidence of non-penetrance. There are still, therefore, no convincing reports of non-penetrance after 60 years of age. While our family does show how some families may require no active intervention in their natural life, our subject 401 clearly would not have survived without surgery at 33 years of age. Therefore even in late onset families one must counsel caution with regard to the age at onset and growth patterns of these tumours. Nevertheless, the prolonged period of deafness not requiring intervention would otherwise suggest not only a later onset of tumorigenesis, but also a much slower growth pattern associated with the family mutation. The isolation of the mutation in this family may be of benefit in counselling other families with the same or similar mutations. It is also of interest that apart from 401 there is a virtual absence of cutaneous and ophthalmic manifestations in the family, as appears to be the case in the milder phenotypes. ${ }^{1}$

We are grateful to the many clinicians involved with this family including Mr B C S Whitfield, Mr D A Moffat, Mr D G Hardy, Dr E Maher, Mr R Lye, and Dr P Crawshaw who also read the manuscript.

1 Evans DGR, Huson S, Donnai D, et al. A clinical study of type 2 neurofibromatosis. $O \mathcal{F}$ Med 1992;84:603-18.

2 Kanter WR, Eldridge R, Fabricant R, Allen JC, Koerber T.

Central neurofibromatosis with bilateral acoustic neuroma: genetic, clinical and biochemical distinctions from oma: genetic, clinical and biochemical distinctions from

3 Evans DGR, Huson S, Donnai D, et al. A genetic study of type 2 neurofibromatosis. II Guidelines for genetic
of counselling. F. Med Genet 1992;29:847-52.

4 Eldridge R, Parry DM, Kaiser-Kupfer MI. Neurofibromatosis 2: clinical heterogeneity and natural history in 39 individuals in 9 families and 16 sporadic cases. $A m$ f Hum Genet 1991;49:32.

5 Rouleau GA, Merel P, Lutchman M, et al. Alteration in a new gene encoding a putative membrane-organising protein causes neurofibromatosis type 2. Nature 1993;363:515-21.

6 Troffater JA, MacCollin MM, Rutter JL, et al. A novel Moesin-, Ezrin-, Radixin-like gene is a candidate for the neurofibromatosis 2 tumor suppressor. Cell 1993;72:791800.

7 Jacoby LB, MacCollin M, Louis DN, et al. Exon scanning for mutation of the NF2 gene in schwannomas. Hum for mutation of the NF2

8 Weissenbach J, Gyapay G, Dib C, et al. A second generation map of the human genome. Nature 1992;359:794-801.
mats

map of the human genome. Nature 1992;359:794-801.
Worster-Drought C, Dickson WEC, McMenemey WH.

Worster-Drought C, Dickson WEC, McMenemey WH.
Multiple meningeal and perineural tumours with anaMultiple meningeal and perineural tumours with analogous changes in the glia and ependy
fibroblastomatosis). Brain 1937;60:88-117.

10 Bourn D, Carter SA, Mason S, et al. Germline mutations in the neurofibromatosis type 2 tumour suppressor gene. Hum Molec Genet 1994;5:813-6.

11 MacCollin M, Mahoney T, Troffater J, Wertelecki W, Ramesh V, Gusella J. DNA diagnosis of neurofibromatosis 2 . Altered coding sequence of the merlin tumor suppressor in an extended pedigree. $\mathscr{f} A M A$ 1993;270:2316-20.

12 Watson C, Gaunt L, Evans G, Harris R, Strachan T. A germinal interstitial deletion maps the locus for type 2 neurofibromatosis to the interval between D22S56 and LIF (leukaemia inhibitory factor). Hum Molec Genet 1993; 2:701-4.

13 Irving RM, Moffat DA, Hardy DG, Barton DE, Xuereb JH, Maher ER. Somatic gene mutations in familial and non-familial vestibular schwannoma. Hum Molec Genet 1994;3:347-50.

14 Narod SA, Parry DM, Parboosingh J, et al. Neurofibromatosis type 2 appears to be a genetically homogenous

15 Ruttledge MH, Narod SA, Dumanski JP, et al. PreRuttledge MH, Narod SA, Dumanski JP, et al. Pre-
symptomatic diagnosis for neurofibromatosis 2 with chrosymptomatic diagnosis for neurofibromatosis 2 with
mosome 22 markers. Neurology 1993;43:1753-60.

16 Gardner WJ, Frazier $\mathrm{CH}$. Bilateral acoustic neurofibromas: a clinical study and field survey of a family of five generations with bilateral deafness in thirty eight members. Arch Neurol Psychiatry 1930;23:266-302.

\section{Appendix}

Linkage. Two STR markers flanking the NF2 gene were used for linkage analysis, D22S275 (proximal) and D22S280 (distal). ${ }^{5}$ PCR was carried out in $10 \mu \mathrm{l}$ volumes using $25 \mathrm{ng}$ of genomic DNA, $5 \mathrm{pmol}$ of each primer, $200 \mu \mathrm{mol} / 1$ of each dNTP, $0 \cdot 2 \mathrm{U}$ Taq polymerase (Life Technologies) in a $1 \times$ PCR reaction buffer $(100 \mathrm{mmol} / 1$ Tris- $\mathrm{HCl}$, pH 9.0 , $20 \mathrm{mmol} / 1$ ammonium sulphate, $1.5 \mathrm{mmol} / 1$ magnesium chloride). PCR cycling conditions were initial denaturation $93^{\circ}$ : three minutes, 30 cycles of $93^{\circ}$ : one minute, $60^{\circ}(\mathrm{D} 22 \mathrm{~S} 275)$ or $50^{\circ}(\mathrm{D} 22 \mathrm{~S} 280)$ : one minute, $72^{\circ}$ : one minute, and a final elongation of $72^{\circ}$ : five minutes. D22S280 PCR products were reduced in molecular weight by digesting with 2 units of the restriction enzyme MseI (New England Biolabs) for four hours. Protein was removed from all PCR reactions by extraction with $15 \mu \mathrm{l}$ of phenol:chloroform $(1: 1)$. Before electrophoresis $2.5 \mu \mathrm{l}$ of a sucrose based loading buffer was added to each sample. The STR markers were electrophoresed on $1 \mathrm{~mm}$ thick, $12 \mathrm{~cm}, 8 \%$ (19:1) native polyacrylamide gels at $50 \mathrm{~mA}$ constant current for approximately 90 minutes and subsequently visualised by silver staining. STR alleles were not sized but assigned a ranking within the family, allele " 1 " for each marker being designated that of highest molecular weight.

Risk calculations were made using the MLINK computer program and assumed an NF2 gene frequency of 1:40000 and the following locus order and recombination fractions: 22 cen-D22S275-(0.5cM)-NF2-(2.5cM)D22S280-22qter. ${ }^{8}$

Mutation analysis. Genomic DNA samples prepared from peripheral blood were amplified with primers for all 16 exons of the NF2 gene, using primers previously described. ${ }^{8}$ PCR reactions were performed in a total reaction volume of $25 \mu \mathrm{l}$ using $100 \mathrm{ng}$ genomic DNA, $20 \mathrm{pmol}$ of each primer, $200 \mu \mathrm{m}$ of deoxyribonucleoside triphosphate, $0.5 \mathrm{U} \mathrm{Tbr}$ polymerase, (Northumbria Biologicals Ltd), $1 \times$ reaction buffer (Northumbria Biologicals Ltd) overlaid with mineral oil. Amplification was performed on a PCR 480 Perkin Elmer Cetus machine ( 35 cycles of $95^{\circ}$ for 90 seconds, $50^{\circ}$ for 90 seconds, and $72^{\circ}$ for 30 seconds followed by a final elongation step of $72^{\circ}$ for 10 minutes).

SSCP analysis was carried out by HydrolinkMDE gel (AT Biochem) electrophoresis according to the supplier's instructions. Samples 
for SSCP analysis ( $3 \mu$ l of PCR product) were diluted with $3 \mu$ l of a solution containing $95 \%$ formamide, $20 \mathrm{mmol} / 1$ EDTA, $20 \mathrm{mmol} / 1$ $\mathrm{NaOH}, 0.05 \%$ bromophenol blue, and $0.05 \%$ xylene cyanol, and denatured at $95^{\circ}$ for three minutes. Electrophoresis was carried out on $24 \mathrm{~cm}$ vertical and $1 \mathrm{~mm}$ thick gels at a constant voltage of $250 \mathrm{~V}$ for 13 to 16 hours. Gels were silver stained by sequential incubations in $10 \%$ ethanol and $0.5 \%$ acetic acid $(2 \times 3$ minutes $)$, $0 \cdot 1 \%$ silver nitrate ( 15 minutes), $1.5 \% \mathrm{NaOH}$ and $0.15 \%$ formaldehyde (20 minutes), and $0.75 \%$ sodium carbonate (10 minutes) and photographed as appropriate. 